\title{
A PRÁTICA DE ENSINO E 0 ESTÁGIO SUPERVISIONADO NA CONSTRUÇÃO DOS SABERES NECESSÁRIOS À DOCÊNCIA
}

\author{
THE TEACHING PRACTICE AND SUPERVISED INTERNSHIP IN THE \\ CONSTRUCTION OF KNOWLEDGE REQUIRED FOR TEACHING
}

\section{LA PRÁCTICA DE LA ENSEÑANZA Y LAS PRÁCTICAS PROFESIONALES SUPERVISADAS EN LA CONSTRUCCIÓN DE LOS SABERES NECESARIOS A LA DOCENCIA}

Gislene Miotto Catolino Raymundo*

\begin{abstract}
Resumo: O presente trabalho pretende analisar a possibilidade de a Prática de Ensino e o Estágio Supervisionado contribuírem para a construção de saberes docentes, estimulando o futuro professor a desenvolver uma postura investigativo-reflexiva necessária para a resolução das situações complexas do cotidiano escolar. Dessa forma, verificou-se o quanto a Prática de Ensino e o Estágio Supervisionado contribuem para a ressignificação de saberes necessários à qualificação da prática pedagógica no curso de Pedagogia de uma instituição de Ensino Superior, localizada no norte do Paraná. Para o desenvolvimento desta pesquisa, nós optamos por uma abordagem de cunho qualitativo que será fundamentada em uma bibliografia sobre a formação de professores, também será realizada a coleta de dados por meio de análise documental e questionários aplicados aos docentes e acadêmicos da instituição. A realização deste estudo apontou que a Prática de Ensino e o Estágio Supervisionado constituem tempo e espaço de aprendizagem significativa durante o processo formativo do futuro professor. Assim, não são apenas atividades extracurriculares realizadas para o cumprimento de uma carga horária de forma isolada e descontextualizada do curso, mas práticas que permitem o desenvolvimento de diferentes compreensões sobre a realidade escolar.
\end{abstract}

Palavras-chave: Estágio Supervisionado. Prática de Ensino. Saberes Docentes.

\begin{abstract}
This study aimed to examine the possibility of the Teaching Practice and Supervised Internship in contributing to build teaching knowledge, encouraging future teachers to develop an investigative and reflective posture required to resolve complex situations of everyday school life. Thus, it was found that the Teaching Practice and Supervised Internship contribute to the reframing of the knowledge necessary for the qualification of pedagogical practice in the Pedagogy course of an institution located in northern Paraná. For the development of this research, we opted for a qualitative approach that is grounded in literature on teacher training, also we will collect data through documental analysis and questionnaires answered by the teachers and students of the institution. This study showed that the Teaching Practice and Supervised Internship provide time and space for meaningful learning during the training process of future teachers. Thus, these are not just activities outside the classroom made for the fulfillment of a isolated workload out of the course's context, but they allow them to develop different understandings about the school reality.
\end{abstract}

Keywords: Supervised Internship. Teaching Practice. Teaching Knowledge.

\footnotetext{
* Doutora em Educação pela PUC-SP. Professora do Instituto Federal Catarinense. E-mail: gismiotto@gmail.com
} 
Resumen: Este artículo de investigación pretende analizar la posibilidad de la Práctica de la Enseñanza y las Prácticas Profesionales Supervisadas en contribuir en la construcción de los saberes docentes, al estimular el futuro profesor a desarrollar una postura investigativa-reflexiva para la resolución de las situaciones complejas del cotidiano en las escuelas. De esa manera, se verificó como la Práctica de la Enseñanza y las Prácticas Profesionales Supervisadas contribuyen para una nueva significación de saberes necesarios a la cualificación de la práctica pedagógica en la carrera de Pedagogía de una institución de educación superior en el norte de Paraná, Brasil. Para el desarrollo de la investigación, se ha optado por un abordaje cualitativo que tendrá una bibliografía sobre la formación de los profesores, y también se buscará los datos por medio de un análisis documental y encuestas aplicadas a los docentes y académicos en la institución. Los resultados muestran que la Práctica de la Enseñanza y las Prácticas Profesionales Supervisadas analizadas constituyen tiempo y espacio de aprendizaje significativo durante el proceso formativo del futuro profesor. Así, muestran que no son solamente actividades extracurriculares realizadas para el cumplimento de una carga horaria aislada y descontextualizada en la carrera, sino que permiten el desarrollo de distintas comprensiones sobre la realidad de las escuelas.

Palabras clave: Prácticas Profesionales Supervisadas. Práctica de la Enseñanza. Saberes Docentes.

\section{Introduzindo a questão}

A proposta de discussão desta pesquisa expressa o entendimento de que a Prática de Ensino e o Estágio Supervisionado constituem componentes curriculares que podem contribuir para a construção de saberes durante o processo formativo e, assim, formar profissionais competentes e cidadãos capazes de solucionar os desafios existentes na dinâmica interna da sala de aula.

Dessa forma, pesquisar sobre a formação de professores, especificamente sobre a formação inicial, configura-se uma empreitada difícil e complexa diante dos inúmeros fenômenos que compõem o processo de formação docente. Porém, optar por um fenômeno não significa desvalorizar ou desprezar as demais possibilidades no mesmo objeto de estudo, pelo contrário, significa lançar um olhar mais rigoroso para esse fenômeno escolhido com o objetivo de desvendar suas complexidades, ultrapassando as dimensões da pura constatação, buscando compreendê-lo de tal forma que favoreça novas possibilidades de concebê-lo.
Assim, este estudo analisa as possibilidades de contribuição da disciplina de Prática de Ensino e do Estágio Supervisionado para a construção de saberes necessários à docência, fornecendo aos futuros docentes as competências para a resolução das situações complexas existentes do cotidiano escolar.

Dessa forma, esta pesquisa pretende contribuir para as discussões que estão sendo realizadas em diversos estudos sobre a formação dos profissionais da educação. Apesar de existir certa produção bibliográfica sobre a formação inicial do professor e as práticas de Estágio Supervisionado, ainda há certa carência de estudos que as relacionem à formação inicial do professor. Dentre essas produções, cito os estudos desenvolvidos por Behrens (1991), Schön (1992), Alarcão (1996), Nóvoa (1992), Gimeno Sacristán (1999), Tardif (2005), Candau e Lelis (1983), Piconez (1991), Freitas (1992, 1996), Lima (2002), Pimenta e Lima (2004) e André (2006), entre outros, que têm contribuído para que as práticas de formação de professores sejam repensadas e novas alternativas sejam apontadas. 
Para o desenvolvimento deste estudo se optou por uma abordagem de cunho qualitativo, pois esta permite ao pesquisador uma melhor compreensão de valores, opiniões, crenças e atitudes que sustentam a postura, a visão de mundo e as relações entre os sujeitos envolvidos e a significação que esses sujeitos atribuem ao fato estudado, o que consiste em um instrumento fundamental para desvelar a complexidade da realidade investigada.

Chizzotti (2006, p. 28-29) constitui o referencial quanto à definição de pesquisa qualitativa quando afirma que:

O termo qualitativo implica uma partilha densa com pessoas, fatos e locais que constituem objetos de pesquisa, para extrair desse convívio os significados visíveis e latentes que somente são perceptíveis a uma atenção sensível. Após este tirocínio, o autor interpreta e traduz em um texto zelosamente escrito, com perspicácia e competências científicas, os significados patentes e ocultos do seu objeto de pesquisa.

Bogdan e Biklein (1994) declaram que esse tipo de pesquisa tem como fonte direta de dados o ambiente natural e o pesquisador, seu principal instrumento, uma vez que mantém contato prolongado com a situação investigada. A coleta de dados envolve a obtenção de dados descritivos, pois se vale de descrições de pessoas, fatos e situações, de transcrições de entrevistas e depoimentos, e exige grande atenção do pesquisador, o qual deve enfatizar mais o processo de construção do conhecimento do que o produto final.

Neste estudo também foi realizada a análise documental por meio do levantamento de dados do Projeto Pedagógico, planos de ensino e relatórios de estágio do curso de Pedagogia da instituição pesquisada, constatando a concepção de Estágio
Supervisionado expressa nesse documento, bem como os textos legais - LDB, pareceres, resoluções e portarias do Conselho Nacional de Educação.

Segundo Lüdke e André (1986, p. 39),

os documentos constituem também uma fonte poderosa de onde podem ser retiradas evidências que fundamentem afirmações e declarações do pesquisador. Não são apenas uma fonte de informação contextualizada, mas surgem num determinado contexto e fornecem informações sobre esse mesmo contexto.

Também foi aplicado um questionário para quatro professores que trabalham diretamente com a Prática de Ensino e o Estágio Supervisionado e para dez alunos do último ano do curso de Pedagogia de uma instituição de Ensino Superior, localizada no norte do Paraná, buscando verificar as possibilidades de contribuição da disciplina de Prática de Ensino e o Estágio Supervisionado na construção de saberes necessários à docência. Esses alunos, no decorrer do curso de Pedagogia, tiveram a oportunidade de (re)construir saberes necessários à docência, podendo confirmar ou não se o Estágio Supervisionado e a Prática de Ensino contribuem para a (res) significação de saberes necessários à qualificação da prática pedagógica.

Assim, os dados coletados através da análise documental e do questionário foram analisados criteriosamente. Isso exigiu da pesquisadora o que os antropólogos chamam de estranhamento:

Um esforço deliberado de distanciamento da situação investigada para tentar apreender os modos de pensar, sentir, agir, os valores, as crenças, os costumes, as práticas e produções culturais dos sujeitos ou grupos estudados. (ANDRÉ, 2005, p. 26). 
A escolha por essa instituição de ensino e por esse curso se deve ao fato de que a pesquisadora era a responsável pela formação de professores nesta instituição e vivenciava situações que permitiam identificar limites e possibilidades para a construção de saberes por meio da Prática de Ensino e do Estágio Supervisionado.

Na empreitada de desenvolver essa pesquisa, foram vivenciados momentos significativos ao analisar, a partir de uma realidade institucional, a possibilidade de o Estágio Supervisionado e a Prática de Ensino constituírem espaço e tempo importantes no processo formativo do futuro professor, pois lhe permitem a construção de saberes práticos e teóricos, bem como a compreensão e reflexão sobre as relações no ambiente escolar, necessários à docência na educação básica.

\section{A prática de ensino e o estágio supervisionado na formação de professores}

Piconez (1991), Freitas (1992; 1996), Pimenta (1997), que pesquisam sobre a Prática de Ensino e o Estágio Supervisionado na formação de professores, têm revelado que o modelo predominante na organização curricular dos cursos de formação de professores se fundamenta no agrupamento das disciplinas do bloco teórico, ministrado no início do curso, ficando para o final as disciplinas do bloco prático. Assim, primeiro o aluno recebe a formação básica e com esses conhecimentos ele obtém a formação pedagógica que o habilitará ao exercício da docência. Esse tipo de preparação de professores parece uma tarefa fácil que se desenvolve rapidamente, no entanto, pesquisas realizadas nessa área ${ }^{1}$ demonstram que o

${ }^{1}$ Há diversas pesquisas publicadas discutindo essa processo de formação de professores não é estabelecido de um momento para o outro, mas demanda tempo e necessita de uma relação dialética entre as disciplinas do curso que possibilitam aos futuros docentes uma nova dimensão do trabalho de sala de aula.

Sabe-se que existem disponibilizadas na literatura muitas alternativas de entendimento sobre a Prática de Ensino e o Estágio Supervisionado enquanto eixos articuladores da formação dos profissionais da educação. Desde 1987, está expresso no documento do MEC/SESu que o estágio, forma com que se concretiza a Prática de Ensino das licenciaturas, constitui um processo criador, de investigação, explicação, interpretação e intervenção na realidade. Os estudos desenvolvidos por Schön (1992), Alarcão (1996), Nóvoa (1992), Freitas (1996), Lima (2002), Pimenta (2004) e Tardif (2005), entre outros, também têm contribuído para que as práticas de formação de professores sejam repensadas e novas alternativas sejam apontadas.

No entanto, o que se verifica nos cursos de formação docente é que esses componentes curriculares predominam como elementos estanques, isolados do conjunto composto pelos demais componentes do curso, sendo trabalhados de forma fragmentada, impossibilitando a compreensão do conhecimento e da realidade social de forma ampla e integrada.

Autores como Pimenta (1997), Fazenda (1998), Candau e Lelis (1983) e Piconez (1991), entre outros, têm chamado a atenção para as situações precárias de estágios, mesmo dentro de um currículo em que se estabelece a docência como base da formação de professores. As dificuldades são muitas, desde a falta de orientação e

temática, destacam-se: Fazenda e Piconez (1991); Pimenta (1997); Neto e Maciel (2002); Pimenta e Lima (2004); Miranda e Silva (2008); entre outros. 
fundamentação prática e teórica dos estagiários para realizar as atividades de estágio, advindas da não integração das universidades com as escolas - campo de estágio - até as limitações impostas pelo estágio convencional: observação, participação e regência. A essas dificuldades se somam outras que, decorrentes das mudanças no contexto social na política educacional e na legislação, apontam para a necessidade de se pensar o estágio como foco de análise, isto é, como eixo articulador de estudos teóricos dos cursos de Formação de Professores e da prática vivenciada nas escolas, possibilitando a construção de saberes necessários à formação docente.

Dessa forma, o estágio pode deixar de ser um treino e aplicação de técnicas para se constituir um dos momentos da formação do futuro professor, que vivencia limites e possibilidades de um fazer pedagógico significativo, proporcionando oportunidades educativas que articulam teoria e prática, levando-o a refletir sobre sua ação profissional, apropriando-se da realidade escolar social na qual está inserido.

Como afirma Pimenta (1997, p.74),

o estágio não se resume à aplicação imediata, mecânica e instrumental de técnicas, rituais, princípios e normas aprendidas na teoria. A prática não se restringe ao fazer, ela se constitui numa atividade de reflexão que enriquece a teoria que lhe deu suporte. O estágio é um processo criador de investigação, explicação, interpretação e intervenção na realidade.

Assim, quando se trabalha a teoria e a prática de forma articulada, o estágio pode contribuir para a construção de conhecimentos e para a melhoria da qualidade de ensino. Essa articulação também contribui para a formação de um profissional com domínio dos conhecimentos específicos e pedagógicos, que fará de sua prática um processo contínuo de investigação.

\section{Prática de ensino e o estágio supervisionado na construção dos saberes necessários à docência}

O Estágio Supervisionado constitui um componente integrante do currículo dos cursos de licenciatura, sendo concebido como tempo e espaço de aprendizagem e não apenas como uma atividade extracurricular realizada para o cumprimento de uma carga horária isolada e descontextualizada do curso. Ao mesmo tempo em que integra prática e teoria, o estágio colabora para que o futuro professor compreenda e reflita sobre as complexas relações que ocorrem no ambiente escolar, seu futuro locus profissional.

Nessa perspectiva, o estágio, assim concebido e estruturado, constitui um verdadeiro “espaço-aula” e não apenas uma oportunidade de aplicar os fundamentos disciplinares adquiridos no curso de formação (PACHECO; MASETTO, 2007). Dessa forma,

o estágio coloca-se em posição de destaque porque proporciona ao aprendiz um desenvolvimento de suas competências profissionais, atuando em ambientes próprios de sua futura profissão. Ao mesmo tempo em que integra prática e teoria, o estágio colabora para que o aprendiz viva o ambiente, o cenário, os personagens, os grupos, os companheiros, o ambiente físico, os problemas e as questões do dia-a-dia de sua profissão. (PACHECO; MASETTO, 2007, p. 143).

Fazenda (1998) declara que os cursos de licenciatura, especialmente os de Pedagogia, devem trabalhar para ir além dos métodos e técnicas e formar o educador/ 
docente entendido como profissional com sólida formação epistemológica, capaz de articular teoria e prática, dispondo das habilidades de um investigador para equacionar a prática pedagógica a fim de que possa exercer criticamente a cidadania, mediante uma visão global de mundo, e enfrentar os problemas da realidade atual.

Dessa forma, o processo de formação docente requer a mobilização dos saberes teóricos e práticos capazes de propiciar ao futuro professor a investigação de sua própria atividade e, a partir dessa realidade, possa constituir seus saberes num processo contínuo, de modo a se colocar como sujeito de suas práticas.

Neste sentido, constata-se que o processo de formação proporcionou-lhes perceber que a

disciplina de Prática de Ensino da Educação Infantil e Séries Iniciais do Ensino Fundamental e o Estágio Supervisionado proporcionam aos seus acadêmicos um embasamento teórico sobre os aspectos pedagógicos que envolvem o processo educativo, e, além disso, propicia o envolvimento dos alunos em situações escolares reais, sendo possível conhecer a dinâmica de uma instituição escolar, através do Estágio Supervisionado. (RELATÓRIO DE ESTÁGIO², 2007, p. 23).

A análise dos questionários também apontou que os discentes consideram a realização do Estágio Supervisionado significativa para o processo formativo, envolvendo aspectos que extrapolam a simples realização de uma carga horária, pois estabelece uma rede de relações entre os conhecimentos teóricos problematizados nos cursos de formação e a realidade social vivenciada nas

\footnotetext{
${ }^{2}$ Os relatórios de estágio utilizados nesta pesquisa foram produzidos pelos alunos do curso de Pedagogia da instituição pesquisada.
}

escolas. No depoimento a seguir, pode-se constatar essa concepção:

Considero a realização do estágio supervisionado extremamente importante dentro do curso de Formação de Professores, pois para os acadêmicos que ainda não atuam na área, o estágio oferece a prática e, para quem já atua, dá a oportunidade de confrontar a forma de atuar em sala de aula com a de outros educadores, como também nos permite relacionar teoria e prática. (A-9) ${ }^{3}$.

\begin{abstract}
Além disso, leva-se em consideração que inicialmente, quando é feita a observação, conseguimos fazer a relação teoria e prática, principalmente porque levamos as discussões para nossa sala de aula. Com o tempo, a teoria fica presente o tempo todo na prática. (A-8).
\end{abstract}

Para os acadêmicos, o estágio também constitui situações de expectativas, estudos, pesquisas, discussões, reflexões, amizades, desafios, insegurança, enfim, muitas outras possibilidades que fazem da vivência do Estágio Supervisionado no curso de formação inicial um momento de crescimento e de experiências que agregam conhecimento significativo ao futuro docente. Todos esses atributos vivenciados pelo estágio são identificados nas afirmações selecionadas a seguir:

Toda realidade nova traz consigo desafios, expectativas, encontros, desencontros, superações e aprendizagens. É quase impossível ficar ileso diante das situações que a vida oferece. O Estágio Supervisionado proporcionou a vivência de todos os

\footnotetext{
${ }^{3}$ Com o intuito de manter sigilosa a identificação dos participantes desta pesquisa os sujeitos - sendo dez acadêmicos, denominados pela letra $\mathrm{A}$ e numerados (A1, A2, A3, A4, A5, A6, A7, A8, A9 e A10) e quatro professores, denominados pela letra $\mathrm{P}$, sendo também numerados (P1, P2, P3 e P4).
} 
aspectos mencionados. (RELATÓRIO DE ESTÁGIO, 2007, p. 84).

As minhas expectativas eram de ter um domínio teórico e prática acerca do curso escolhido que me proporcionasse condições de atuação profissional na área. De certa forma elas foram atendidas, apesar de alguns momentos me sentir incapaz de agir frente aos desafios da realidade educacional. (RELATÓRIO DE ESTÁGIO, 2009, p. 31).

O estágio é também momento de partilha, socialização, trocas de experiências e conhecimentos vivenciados e apreendidos, enfim, de todos os sentimentos que o acadêmico estabelece com os professores regentes, os professores do curso de formação e os alunos da escola. Todas as relações que ocorrem em sala de aula, em um contexto social concreto, também fazem parte do processo de formação docente (MONIZ, 2010). Nesta perspectiva, há expectativas e trocas de conhecimentos e experiências como explicitado no relato abaixo:

Após aplicarmos o projeto, obteremos os resultados e retornaremos à sala de aula no Curso de Pedagogia para socializarmos nossas experiências com nossos colegas, onde cada qual irá expor seu projeto e as atividades realizadas, compartilhando as dificuldades e êxitos obtidos. (RELATÓRIO DE ESTÁGIO, 2006, p. 52).

A Prática de Ensino e o Estágio Supervisionado também devem constituir um espaço e tempo de construção de aprendizagens significativas no processo de formação inicial de professores. Essa construção não ocorre de forma isolada, mas concomitantemente com as disciplinas teóricas realizadas nos cursos de formação, permeada pelo processo de reflexão. Nesta perspectiva, Freire (2001, p. 2) declara que:
Assim, o estágio pedagógico ao possibilitar o envolvimento experiencial e interactivo com alunos na sala de aula e com os orientadores, em situações pré e pós-activas do ensino cria condições para a realização de aprendizagens que podem proporcionar a aquisição de saberes profissionais e mudanças, quer nas estruturas conceptuais, quer nas concepções de ensino.

No entanto, para que o estágio se apresente como uma possibilidade de construção de conhecimentos necessários à docência, é imprescindível que esteja organizado de tal forma que proporcione ao futuro professor um profundo conhecimento da realidade, para que este possa conhecer e compreender sua complexidade e posicionar-se criticamente perante os acontecimentos sociais e escolares. Além disso, esse futuro professor deve ter sólida fundamentação teórica, por meio da qual estabelecerá relações com o contexto real da sala de aula, permitindo-lhe interpretá-la e intervir de forma consciente e planejada. Desta forma, o Estágio Supervisionado, como campo de conhecimento e eixo estruturante da formação de professores, possibilita a construção de saberes fundamentados na unidade entre teoria e prática.

Entretanto, para possibilitar a construção de saberes, não é suficiente encaminhar o acadêmico à escola, é imprescindível que antes, durante e depois da realização das etapas de observação, participação e regência seja destinado espaço e tempo no currículo do curso de formação para o diálogo e a análise crítica, no intuito de integrar a realidade vivenciada na escola com os elementos estudados no curso de formação. Esse momento é considerado primordial no processo de formação inicial. Na instituição pesquisada, esse processo pode ser confirmado por meio dos relatos a seguir: 
Com apoio da professora regente, verificaremos os conteúdos trabalhados durante o primeiro e segundo bimestres e tentaremos definir o perfil da turma para que possamos elencar os temas prováveis para aplicação do projeto de estágio. Feito isso, retornaremos à sala de aula (Curso de Pedagogia) para, juntamente com as professoras das Metodologias e Prática de Ensino, socializarmos os relatórios e receber as orientações para elaboração do projeto de estágio. (RELATÓRIO DE ESTÁGIO, 2007, p. 52).

Após a aplicação do projeto, iremos à sala de aula (IES) socializar e refletir sobre os resultados obtidos e, posteriormente, registraremos tais reflexões em um relatório crítico-informativo. (RELATÓRIO DE ESTÁGIO, 2008, p. 43).

Diante desses relatos, fica explícito que a construção de conhecimentos ocorre enquanto as experiências vivenciadas nos estágios são discutidas e teorizadas em momentos que têm essa finalidade, durante o processo de formação inicial. Sendo assim, não basta encaminhar o acadêmico à escola, mas é necessário que os conhecimentos da realidade escolar, adquiridos pelos alunos, sejam considerados no currículo do curso de formação, havendo, desta forma, uma interação entre a realidade profissional e os fundamentos teóricos estudados no curso.

No entanto, salienta-se que somente por meio do estágio curricular não será possível desenvolver todos os saberes necessários ao exercício da docência. Segundo Tardif (2002), os professores possuem, desenvolvem e adquirem saberes variados, que provém de várias fontes e diferentes momentos da história de vida e da carreira profissional. Neste sentido, o professor se serve de

cultura pessoal, que provém de sua história de vida e de sua cultura escolar anterior; ele também se apoia em certos conhecimentos disciplinares adquiridos na universidade, assim como em certos conhecimentos didáticos e pedagógicos oriundos de sua formação profissional; ele se apoia também naquilo que podemos chamar de conhecimentos curriculares veiculados pelos programas, guias e manuais escolares; ele se baseia em seu próprio saber ligado à experiência de trabalho, na experiência de certos professores e em tradições peculiares ao ofício de professor. (TARDIF, 2002, p. 13).

Sobre a produção de saberes no processo de formação inicial, Freire (1996) argumenta sobre a necessidade de compreensão por parte do professor de que um dos saberes indispensáveis para a prática docente é assumir-se como sujeito também da produção do saber, compreendendo que ensinar não é transferir conhecimento, mas mobilizar uma diversidade de saberes e criar possibilidades para sua produção ou construção.

A partir dessas considerações sobre saberes, pode-se afirmar que, durante o processo de formação inicial, o estágio é “parte desta cadeia formativa presente na vida dos que optam pela docência, ao longo da trajetória profissional” (AROEIRA, 2009, p. 127).

Neste sentido, a Prática de Ensino e o Estágio Curricular, como espaço de aprendizagem, são apresentados pelos acadêmicos enfatizando a construção de saberes que ocorrem tanto na instituição formadora quanto na realização do estágio nas escolas de educação básica:

Diante de todas as fases executadas, pode-se concluir que tal parceria foi de suma importância, tanto para os acadêmicos quanto para os alunos da escola campo de estágio - Modalidade Normal, ambas, futuros profissionais da educação. Para os primeiros, significou uma 
vivência significativa no nível de ensino que poderão atuar posteriormente e também o conhecimento de uma prática pedagógica diferenciada. (RELATÓRIO DE ESTÁGIO, 2006, p. 97).

Na formação inicial, o estágio pode se constituir em tempo e espaço de reflexão sobre a prática pedagógica do futuro professor, ampliando sua capacidade de gerar conhecimento pedagógico por meio da análise do seu fazer docente. Nesta perspectiva, os próprios acadêmicos consideram que o estágio não pode ser concebido como uma simples instrumentalização técnica, pois constitui um aprendizado permanente para o futuro professor na medida em que as questões presentes no cotidiano escolar são sempre singulares e novas respostas precisam ser encaminhadas para a resolução de situações reais.

E, durante este período [estágio], pudemos compartilhar construções de aprendizagens, bem como fazer relação entre o aprendizado teórico e a prática. Desta forma, esse momento significativo não se limitou apenas ao treino de técnicas e habilidades, mas proporcionou conhecimentos específicos e pedagógicos para atuação comprometida e ética no processo ensino e aprendizagem. (RELATÓRIO DE ESTÁGIO, 2009, p. 51).

Entretanto, é preciso salientar que o conhecimento experiencial não se resume somente à aquisição de conhecimentos técnicos padronizados cujos modos operatórios são codificados e conhecidos de antemão, por exemplo, em forma de rotinas, procedimentos ou receitas,

mas trata-se de situações novas e únicas que podem ser enriquecidas, quando articuladas a um processo permanente de reflexão e discernimento para que possa não só compreender o problema como também organizar e esclarecer os objetivos almejados e os meios a serem usados para atingi-los. (TARDIF, 2002, p. 7).

Segundo Pimenta e Lima (2004, p. 61), o Estágio Supervisionado

como campo de conhecimento e eixo curricular central nos cursos de formação de professores possibilita que sejam trabalhados aspectos indispensáveis à construção dos saberes e das posturas específicas ao exercício profissional docente.

Assim sendo, o estágio se constitui um espaço de reflexão sobre as práticas observadas a partir das teorias, sendo possível ressignificar seus saberes docentes e assim produzir conhecimentos. Neste sentido, os acadêmicos confirmam a produção desse novo saber ao declararem que:

Ao realizar o estágio, tive a oportunidade de observar diferentes formas de ensinar. Desta forma, pude aprender muito com os professores que já atuam na área há algum tempo. (A-10).

O estágio supervisionado me fez sentir desafiada frente ao novo que iria vivenciar e, em alguns momentos, incapaz de realizá-lo. Mas ele me mostrou que vale a pena enfrentar os desafios, que é possível sim superar as limitações e que ensinar é muito bom. (A-1).

Segundo Tardif (2002, p. 39), os saberes experienciais dos professores são temporais, ou seja, são adquiridos através do tempo e construídos pelos próprios professores no exercício de suas funções e na prática de sua profissão. "São saberes que brotam da experiência e são por ela validados. Incorporamse à vivência individual e coletiva sob a forma de habitus e de habilidades, de saber fazer e de saber ser”. 
No processo de formação inicial, os saberes experienciais são elaborados no estágio, especificamente quando os alunos analisam as experiências acumuladas em sua vida, refletem sobre elas e as relacionam com as vivências do estágio.

Ghedin (2002, p. 135) explica que “os saberes da experiência não são saberes como os demais, eles são formadores de todos os demais”. É na prática refletida (ação e reflexão) que este conhecimento se produz, na inseparabilidade entre teoria e prática. Neste sentido, é possível considerar que os professores constroem, no decorrer de sua trajetória, saberes que nem sempre são ensinados como são as teorias e, portanto, é no espaço de trabalho que são germinados tais saberes. Quanto à produção dos saberes da prática, Chartier (2010, p. 43) também afirma que

para se formar e poder exercer bem a sua profissão, um médico precisa dominar os saberes científicos, obtidos no curso universitário, e os saberes da ação, aprendidos durante o trabalho em hospitais. Ali, ele compartilha com médicos e enfermeiros o atendimento a pacientes. Se ele tiver somente o saber científico, pode até se tornar um bom conhecedor da medicina, mas jamais será um bom médico. Com os professores, ocorre situação semelhante. Ou seja, sem a prática, o educador não será eficiente em sala de aula.

A possibilidade de construir conhecimentos a partir da observação da prática do outro é uma aprendizagem, descrita pelos alunos não como modelo do que se deve e do que não se deve fazer, mas como um saber construído no processo de formação que certamente se tornará uma referência à sua própria prática futura. A construção desta aprendizagem pode ser verificada a partir dos relatos abaixo:
No estágio, me deparei com uma sala de aula heterogênea, isto é, com alunos em diferentes níveis de aprendizagens e aprendi que caberá ao professor propor metodologias que visam alcançar a necessidade de cada aluno. (A-2).

Na atuação do professor, é necessário saber planejar, organizar, liderar frente às situações que o dia a dia impõe saber reagir rapidamente e situações que exigem proatividade nas decisões. Já que o professor precisa de liderança para "impor" uma atividade que foi organizada através de prévio planejamento para que se tenha um resultado satisfatório em sua avaliação. (A-4).

O saber docente se caracteriza como um saber plural, originado

de vários contextos, circunstâncias e instituições, assim como da experiência pessoal e profissional, dos saberes das disciplinas, e atividades práticas proporcionadas pelos cursos de formação. (MIZUKAMI; REALLI, 2002, p. 232).

Na instituição pesquisada, é possível perceber que o Estágio Supervisionado possibilita a construção de saberes em diversas situações e também envolve diferentes atores que participam do processo formativo. No depoimento do acadêmico, observa-se que no momento de orientação na instituição de formação há socialização e partilha de saberes por meio das orientações dos professores de Metodologias e Prática de Ensino.

Estes projetos foram discutidos, refletidos e analisados entre os grupos (acadêmicos) e supervisionados pelos professores de Metodologias e Prática de Ensino da Educação Básica, para que atingissem um nível de qualidade e interdisciplinaridade necessário para elaboração das aulas como um todo. Cada estagiária adequou seu projeto de acordo com o perfil e necessidade da turma. (RELATÓRIO DE ESTÁGIO, 2007, p. 63). 
Em outro relatório, percebe-se que o acadêmico, por meio da explicação da pedagoga da escola, compreende a função do Projeto Político Pedagógico (PPP) e como esse documento está relacionado ao regimento e a sua influência no trabalho realizado pelo professor no contexto escolar.

Para melhor exemplificar a importância do PPP, o pedagogo afirmou que este trabalha em conjunto com o Regimento Escolar, que é um documento onde constam as normas e regras que norteiam o trabalho da instituição. (RELATÓRIO DE ESTÁGIO, 2006, p. 77).

Portanto, percebe-se que a produção e socialização de saberes necessários à docência não têm como locus somente instituições formadoras, mas também estão presentes nas escolas e em outros espaços de desenvolvimento profissional docente.

No relato abaixo, o acadêmico da instituição pesquisada descreve sobre a construção de saberes teóricos e práticos referentes à educação infantil, mediados pelo professor coordenador de estágio. Desta forma, é possível verificar que o processo de reflexão sobre a experiência, à luz da teoria, orientado pelo professor supervisor de estágio, poderá favorecer a construção de novos saberes pelos acadêmicos.

Com o auxílio do professor coordenador de estágio, entramos em contato com linhas teóricas e conhecemos importantes autores sobre aprendizagem e desenvolvimento infantil, bem como competentes Centros de Educação Infantil municipais e suas respectivas políticas educacionais, além de realizar a análise de seu Projeto Político Pedagógico. (RELATÓRIO DE ESTÁGIO, 2009, p. 55).

Acredita-se que a orientação de estágio constitui uma atividade que exige do professor orientador a capacidade de articular conhecimentos teóricos e práticos, possibilitando que os estagiários possam observar, participar e intervir por meio do projeto de estágio de forma crítica e reflexiva, contribuindo com a escola e ressignificando o seu processo de formação.

Nesse sentido, ressalta-se que o trabalho do professor orientador de estágio além das "muitas atribuições é uma tarefa árdua" (P-4). Um dos professores faz o seguinte comentário:

Para ser professor orientador de estágio, você também precisa ter muito conhecimento teórico. Antes de colocar seus alunos para estagiar, você deve orientá-los sobre a ética, postura, responsabilidade e principalmente compromisso que estão assumindo. Seu papel é de mediador, é você quem conduzirá todo processo, desde o contato com a escola, a supervisão dos estagiários no local de seus estágios, enfim, você é o orientador dessa etapa tão importante e deve saber o quanto você é responsável pelo aluno e pelo seu processo de aprendizagem. (P-2).

Nesta perspectiva, o professor orientador de estágio acompanha o aluno à escola, orientando-o no decorrer de todo o processo. Assim, o professor orientador mais do que informa ou transmite conhecimentos, reflete conjuntamente com o futuro professor sobre sua atuação, identificando as teorias presentes em sua prática e intervindo para a construção de uma prática docente reflexiva. Nesse sentido, os momentos de prática e de problematização dos fundamentos teóricos possibilitarão ao acadêmico que já atua como professor da educação básica a reflexão sobre a prática docente observada nas escolas e também sobre sua própria prática pedagógica. 
O processo de reflexão e ressignificação sobre a própria prática docente e consequentemente a produção de saberes necessários à formação docente é percebida pelos professores orientadores de estágio, pois testemunham que:

Pelos próprios relatos destes acadêmicos que atuam na docência e a supervisão que realizamos durante o estágio, percebemos a mudança de postura enquanto profissionais. Os estágios muito têm contribuído para a qualificação destes profissionais, mesmo sendo atuantes. (P-1).

Segundo Masetto (2003a, p. 34), a prática pedagógica não está voltada “apenas para auxiliar o processo de aprendizagem do aluno, mas também para o processo de crescimento e desenvolvimento do professor”. Nesta perspectiva, pode-se inferir que a prática pedagógica constitui fonte de conhecimento e contribui "para a formação contínua e profissional dos docentes”. Por conseguinte, é possível que a construção de saberes necessários à docência constitua produto de sucessivas socializações da prática pedagógica entre as professoras da escola e os futuros docentes, como podemos verificar nos relatos abaixo:

O estágio proporcionou, para mim, contato com realidades educacionais diferentes das que vivenciava. Fez-me aprender com outras pessoas, com profissionais mais experientes e perceber que o mundo da educação tem suas particularidades, mas todos enfrentam desafios. Isso é importante para valorizarmos onde estamos e respeitarmos todas as situações e pessoas. (A-1).

Após as informações obtidas e conforme a solicitação do professor da escola campo de estágio, pesquisou-se as atividades pertinentes ao perfil da sala. (RELATÓRIO DE ESTÁGIO, 2007, p. 41).
Em reunião com o professor regente da escola campo de estágio, foram sanadas as dúvidas e assim traçado o perfil da turma para elaboração do projeto de estágio. (RELATÓRIO DE ESTÁGIO, 2006, p. 46).

Considera-se que a realização do estágio, para os acadêmicos que já exercem a docência, constitui um instrumento que favorece a reflexão sobre a sua própria prática pedagógica como uma autoavaliação, uma vez que, para quem atua como professor, não basta fazer estágio e considerar apenas a prática do outro, é preciso que o estágio também possibilite o confronto do que se vivencia na escola, enquanto estagiário, com o que se vivencia no espaço de trabalho, enquanto profissional. Isso foi percebido pelos acadêmicos quando testemunham que:

para os acadêmicos que ainda não atuam na área, o estágio oferece a prática e, para quem já atua, dá a oportunidade de confrontar a forma de atuar em sala de aula com a de outros educadores. (A-9).

Pimenta (2002, p. 77) declara que para os acadêmicos que já conhecem o interior da escola o estágio é uma possibilidade de ressignificação da identidade profissional que se constrói

com base na significação social da profissão, na revisão constante dos significados sociais da profissão, na revisão das tradições, mas também na reafirmação de práticas consagradas culturalmente que permanecem significativas.

Ao analisar os relatos dos acadêmicos da instituição pesquisada, percebe-se que compreendem que o processo de formação não termina no curso de graduação, mas constitui mais uma etapa, dentre outras, a ser percorrida e que, neste contexto, o professor 
necessita assumir a postura de um eterno aprendiz, convencendo-se de que "ensinar não é transferir conhecimento, mas criar as possibilidades para a sua produção ou a sua construção” (FREIRE, 1996, p. 25). Assim, nos relatórios de estágios são encontradas declarações como essa:

As dificuldades comuns na elaboração e organização de um projeto como este, levaram os acadêmicos a refletirem sobre a importância de transmitir conhecimentos e de reavaliar métodos e concepções educacionais, numa sociedade onde as mudanças são muito rápidas. Portanto, os profissionais da educação devem estar preparados para estas transformações sociais estudando, pesquisando num fazer contínuo e, com isto, enfrentar as adversidades que surgirem ao longo do caminho. (RELATÓRIO DE ESTÁGIO, 2009, p. 61).

Segundo Mizukami et al. (2002), aprender a ensinar e aprender o trabalho docente são processos de longa duração, sem ponto final estabelecido inicialmente, ou seja, a aprendizagem docente "não se constrói como um prédio onde se deve necessariamente começar pela base a acabar pelo teto. Está em constante transformação, em perpétuo movimento, tal como uma sinfonia inacabada”. (BARTH, 1993, p. 66-67).

A continuidade do processo de aprendizagem docente pode ser constatada nos relatos a seguir: "Com o curso superior, as minhas expectativas estão sendo atendidas, porém a continuidade dos estudos continua sendo necessária devido às constantes mudanças da sociedade.” (A-3). Outro acadêmico afirma: "Aprendi muito com meu curso superior e hoje posso dialogar sobre o que aprendi, como também tenho base para continuar meus estudos.” (A-1).
Segundo Pimenta e Lima (2004, p. 228), a realização do estágio sob a forma de projetos possibilita que os acadêmicos desenvolvam um olhar interpretativo sobre as questões da realidade, "uma postura investigativa, uma visão de conjunto do espaço escolar, uma percepção das dificuldades que a escola enfrenta, mas também das conquistas reveladas nas ações dos profissionais que ali se encontram”.

Assim sendo, outra contribuição do estágio supervisionado para a construção da aprendizagem dos acadêmicos se refere à possibilidade de organizar um projeto que viabilize o conhecimento dos problemas e necessidades que afetam o processo de ensino e aprendizagem, especialmente propondo intervenções no aprendizado das crianças, como se pode verificar a seguir:

Esteprojeto será elaborado de forma a tornar a aprendizagem das crianças significativa. Para isso, haverá a necessidade de organizar a prática pedagógica, propondo objetivos, conteúdos, métodos, organizando o tempo e o espaço, além de diversificar materiais e atividades de forma que atendam às necessidades das crianças, dentro de uma perspectiva de desenvolvimento global, integrando aspectos físicos, emocionais, afetivos e sociais, proporcionando-lhes momentos de aprendizagem. (RELATÓRIOS DE ESTÁGIO, 2006, p. 42).

O desenvolvimento do estágio por meio de projeto gera aprendizado tanto para os alunos da escola quanto para os acadêmicos que reconhecem esse aprendizado, ao afirmarem que:

Acredito que ambas as instituições se beneficiaram com o projeto, ou seja, a escola campo de estágio abriu as portas para os acadêmicos, dessa forma, houve uma troca de aprendizagens, tanto para os 
discentes quanto para os alunos da escola campo de estágio. (A-2). explicam:

Pimenta e Lima (2004, p. 228),

A realização dos estágios sob a forma de projetos pode estimular nos estagiários o desenvolvimento de um olhar sensível e interpretativo às questões da realidade, uma postura investigativa, uma visão de conjunto do espaço escolar, uma percepção das dificuldades que a escola enfrenta, mas também das conquistas reveladas nas ações dos profissionais que ali se encontram; uma compreensão da cultura escolar e das relações que ali se estabelecem de conflitos, confrontos e cooperação e participação.

Os projetos de estágio foram realizados conforme as modalidades previstas no projeto pedagógico do curso. Algumas situações vivenciadas na escola que não podem ser determinadas ou modificadas pelas instituições formadoras geram a impressão de que algo poderia ser diferente. Essa impressão pode ser verificada no relato a seguir:

Os projetos de estágios que participei (Formação de Docente do nível Médio, Educação Infantil e Gestão Escolar) tiveram uma boa organização no aspecto geral. Fomos bem acolhidos em todas as Instituições, tivemos uma boa orientação acadêmica dos professores responsáveis e realizamos um longo e árduo trabalho. O único estágio que não correspondeu ao seu objetivo, a meu ver, foi o da gestão. Infelizmente, não tivemos um contato direto da realidade de um coordenador pedagógico, de uma supervisão, apenas uma pincelada geral. Sei também que essa é uma área delicada e nem todas as escolas abrem suas portas, mas esperava maior contato com esse setor escolar. (A-3).
A partir dos relatos dos acadêmicos é possível perceber que a organização da Prática de Ensino e do Estágio Supervisionado por meio de projetos de investigação e intervenção possibilitam ao futuro professor a reflexão em torno da realidade da escola e da sala de aula, tendo em vista o desenvolvimento de propostas coerentes com as necessidades e possibilidades de aprendizagem dos alunos. Esse processo de formação oportuniza ao acadêmico mobilizar vários saberes e (res)significar os conhecimentos e saberes docentes a fim de responder às exigências das situações concretas de ensino no contexto da educação brasileira.

Além da possibilidade de aprenderem a pensar ações pedagógicas direcionadas para intervir na aprendizagem dos alunos da escola, os acadêmicos percebem que toda ação do professor deve ser planejada, considerando como ponto de partida para sua intervenção as possibilidades e necessidades dos alunos em seu contexto social, como se pode constatar nos relatos a seguir:

Portanto, além de compreender se uma atividade está de acordo com a faixa etária de cada aluno, também é preciso saber que em uma sala de aula jamais se encontrará uma turma com alunos homogêneos, isto é, todos iguais, mas que sempre iremos nos deparar com a diferença existente entre eles. Sendo assim, o planejamento da aula do professor tem que ser intencional, ter objetivos, por que e para quê trabalhar determinado conteúdo, respeitado sempre a diferença, seja ela cognitiva, social ou econômica, de cada aluno. (RELATÓRIOS DE ESTÁGIO, 2007, p. 77).

Durante o estágio, os discentes irão se deparar com uma sala de aula heterogênea, isto é, com alunos em diferentes níveis de aprendizagens e caberá a ele propor 
metodologias que visam alcançar a necessidade de cada aluno. (A-2).

Segundo Gasparin (2002), é imprescindível que o professor tenha consciência de que é importante conhecer a realidade e o interesse dos alunos para que assim se evite o distanciamento entre a prática social e os conteúdos escolares. Neste sentido, Freire e Campos (1991, p. 5) afirmam:

O ensino deve sempre respeitar os diferentes níveis de conhecimento que o aluno traz consigo à escola. O educador deve considerar essa 'leitura do mundo' inicial que o aluno traz consigo, ou melhor, em si.

A partir das informações colhidas pelos professores da instituição pesquisada e também pelos acadêmicos, depara-se com uma proposta de formação docente que extrapola as balizas determinadas pelas concepções de aplicação técnica e aponta-se a possibilidade de os acadêmicos, durante o processo de formação inicial, deixarem de ser meros consumidores de conhecimento, podendo produzi-lo numa perspectiva formativa. Como afirma Freire (1996, p. 15),

formar é muito mais do que puramente treinar o educando no desempenho de destrezas, é possibilitar a construção de conhecimentos sobre a prática docente, a partir de um processo constante de reflexão.

Portanto, essa pesquisa foi realizada a partir de uma realidade institucional, por meio dos olhares dos acadêmicos do curso de Pedagogia, dos professores formadores e também da análise de documentos pertinentes deste curso. Dessa forma, buscou-se compreender a concepção de Estágio Supervisionado e de Prática de Ensino enquanto espaço e tempo significativos na formação e construção de saberes práticos e teóricos, vislumbrando, assim, a possibilidade de elaboração e ressignificação desses saberes para a formação do futuro professor da educação básica.

\section{Considerações finais}

A realização deste estudo proporcionou momentos de reflexão muito significativos ao analisar as possibilidades da disciplina de Prática de Ensino e do Estágio Supervisionado constituírem espaço e tempo significativos na construção de saberes práticos e teóricos e não apenas atividades extracurriculares realizadas para o cumprimento de uma carga horária isolada e descontextualizada do curso, vislumbrando, assim, a possibilidade de elaboração e ressignificação desses saberes para a formação do futuro professor da educação básica.

Esse estudo indicou que, durante o processo de formação inicial, é importante que a Prática de Ensino e o Estágio Supervisionado possibilitem a relação entre teoria e prática, constituindo momentos extremamente importantes no processo formativo do futuro professor, pois lhe permite o desenvolvimento de diferentes olhares e compreensões da realidade escolar, bem como o surgimento de inúmeras indagações necessárias à construção e produção do conhecimento.

Nessa perspectiva, compreende-se que a Prática de Ensino e o Estágio Curricular devem propiciar ao aluno não apenas a vivência em sala de aula ou restringir-se à tarefa de ministrar aulas, mas também o contanto com a dinâmica escolar em seus variados aspectos, permitindo a construção de saberes necessários à docência. Dessa forma, o estágio deixa de ser um treino e aplicação de técnicas para se constituir um dos momentos 
da formação do futuro professor. No estágio este docente vivencia limites e possibilidades de um fazer pedagógico que tenha sentido, pois proporciona ao aluno/estagiário oportunidades educativas que articulam teoria e prática, levando-o à reflexão sobre sua ação profissional e sua intencionalidade, além de se apropriar da realidade escolar na qual está inserido.

Portanto, esse estudo permitiu identificar o quanto a Prática de Ensino e o Estágio Supervisionado são concebidos como um momento significativo no processo formativo possibilitando a construção de saberes permitindo ao futuro docente redescobrir a dimensão social de ser professor.

\section{Referências}

ANDRÉ, Marli. Estudo de caso em pesquisa e avaliação educacional. Brasília, DF: Liber Livros, 2005.

ANDRÉ, Marli (Org). O papel da pesquisa na formação e prática dos professores. 5 . ed. Campinas, SP: Papirus, 2006.

ALARCÃO, Isabel (Org.). Formação reflexiva de professores: estratégias de supervisão. Portugal: Porto Codex, 1996.

AROEIRA, K. P. O estágio como prática dialética e colaborativa: a produção de saberes por futuros professores. 2009. 253 f. Tese (Doutorado em Educação: Didática, Teorias de Ensino e Práticas Escolares) Faculdade de Educação da Universidade de São Paulo, São Paulo, 2009.

BARTH, B. M. O saber em construção: para uma pedagogia da compreensão. Lisboa: Instituto Piaget, 1993.

BEHRENS, Marilda Aparecida. O estágio supervisionado de prática de ensino: uma proposta coletiva de reconstrução. 1991.
154 f. Dissertação (Mestrado em Educação: Currículo) - Pontifícia Universidade Católica de São Paulo, PUC/SP, São Paulo, 1991.

BOGDAN, Robert; BIKLEIN, Sari. Investigação qualitativa em educação. Porto: Porto Editora, 1994.

CANDAU, Vera M.; LELIS, Isabel. A relação teoria-prática na formação do educador. Tecnologia Educacional, Rio de Janeiro, v. 55, p. 12-18, nov./dez. 1983.

CHARTIER, A. M. Saberes científicos e saberes de ação precisam caminhar juntos. Revista Nova Escola, Edição 236, p. 41-45, out. 2010.

CHIZZOTTI. A. Pesquisa qualitativa em ciências humanas e sociais. Petrópolis: Vozes, 2006.

GHEDIN, E. Professor reflexivo: da alienação da técnica à autonomia da crítica. In: PIMENTA, S. G.; GHEDIN, E. (Org.). Professor reflexivo no Brasil. São Paulo: Cortez, 2002. p. 129-150.

FAZENDA, Ivani Catarina Arantes. Didática e interdisciplinaridade. São Paulo: Papirus, 1998.

FREIRE, P.; CAMPOS, M. O. Leitura da palavra... leitura do mundo. O Correio da UNESCO, Rio de Janeiro, v. 19, n. 2, p. 4-9, fev. 1991.

FREIRE, Paulo. Pedagogia da autonomia: saberes necessários à prática educativa. 15. ed. São Paulo: Paz e Terra, 1996.

FREIRE, A. M. Concepções orientadoras do processo de aprendizagem do ensino nos estágios pedagógicos. Colóquio: Modelos e Práticas de formação Inicial de Professores, Faculdade de Psicologia e de Ciências da Educação, Universidade de Lisboa. Lisboa, Portugal, 2001. p. 1-25. Disponível em: <http:/www.educ.fc.ul.pt/ 
recentes/mpfip/pdfs/afreire.pdf>. Acesso em: 26 nov. 2011.

FREITAS, Helena Costa Lopes de. Conseguiremos escapar ao neotecnicismo? In: SOARES, M. B. Escola Básica. Campinas: Papirus/CEDES; São Paulo: Ande/ANPED, 1992. p. 91-137.

FREITAS, Helena Costa Lopes de. O trabalho como princípio articulador na prática de ensino e nos estágios. São Paulo: Papirus, 1996.GASPARIN, J. L. Uma didática para a pedagogia histórico-crítica. 3. ed. Campinas: Autores Associados, 2002.

KULCSAR, Rosa. O estágio supervisionado como atividade integradora. In: PICONEZ, Stela C. Bertholo (Org.). A prática de ensino e o estágio supervisionado. São Paulo: Papirus, 1991. p. 63-74.

LIMA, Maria Socorro Lucena (Org.). Dialogando com a escola. Fortaleza: Demócrito Rocha, 2002.

LÜDKE, M.; ANDRÉ, M. Pesquisa em educação: abordagens qualitativas. São Paulo: EPU, 1986.

MACIEL, Lizete Shizue Bomura. A investigação como um dos Saberes Docentes na Formação Inicial de Professores. In: NETO, Alexandre S.; MACIEL, Lizete Bomura. Desatando os nós da formação docente. Porto Alegre: Mediação, 2002. p. 79-92.

MASETTO, Marcos Tarciso. Comentário: a prática pedagógica como fonte de conhecimento. In: QUELUZ, A. G.; ALONSO, M. O trabalho docente. São Paulo: Pioneira, 2003a. p. 19-36.

MIZUKAMI, Maria da Graça Nicoletti; REALI, Aline Maria de Medeiros Rodrigues. Aprendizagem profissional de docência: saberes, contextos e práticas. São Carlos: EdUFSCAR, 2002.
MIZUKAMI, Maria da Graça Nicoletti et al. Escola e aprendizagem da docência: processos de investigação e formação. São Carlos: EdUFSCAR, 2002.

MIRANDA, Maria Irene; SILVA, Lazara Cristina da. Estágio supervisionado e prática de ensino. São Paulo: Junqueira\&Marin, 2008.

MONIZ, Maria Isabel d'Andrade de Sousa. Formação inicial de professores: um estudo de caso sobre a participação de estudantes de Pedagogia no Projeto Bolsa Alfabetização - 2007 a 2009. 2010. 250 f. Tese (Doutorado em Educação: Currículo) Programa de Pós-Graduação em Educação: Currículo. Pontifícia Universidade Católica de São Paulo, PUC/SP, São Paulo, 2010.

NÓVOA, Antonio. Os professores e a sua formação. Lisboa: Dom Quixote, 1992.

PACHECO, $\quad$ C. $\quad$ R. F.; MASETTO, M. T. O estágio e o ensino de engenharia. In: MASETTO, Marcos Tarciso. (Org.). Ensino de engenharia: técnicas para otimização das aulas. São Paulo: Avercamp Editora, 2007. p. 143-165.

PIMENTA, Selma Garrido (Org.). Estágio e docência. São Paulo: Cortez, 2004

. Saberes pedagógicos e atividade docente. São Paulo: Cortez, 2002.

O estágio na formação de professores. São Paulo: Cortez, 1997.

RELATÓRIO DE ESTÁGIO

SUPERVISIONADO. Educação Infantil, Ensino Fundamental e Ensino Médio. Instituição Pesquisada, 2006.

RELATÓRIO DE ESTÁGIO SUPERVISIONADO. Educação Infantil, Ensino Fundamental e Ensino Médio. Instituição Pesquisada, 2007. 
RELATÓRIO DE ESTÁGIO

SUPERVISIONADO. Educação Infantil, Ensino Fundamental e Ensino Médio. Instituição Pesquisada, 2008.

RELATÓRIO DE ESTÁGIO SUPERVISIONADO. Educação Infantil, Ensino Fundamental e Ensino Médio. Instituição Pesquisada, 2009.

GIMENO SACRISTÁN, José. Poderes instáveis em educação. Porto Alegre: Artmed, 1999.

SCHÖN, Donald Formar professores como orofissionais reflexivos. In: NÓVOA, A. Os professores e sua formação. Lisboa: Dom Quixote, 1992. p. 77-93.

TARDIF, Maurice. O trabalho docente: elementos para uma teoria da docência como profissão de interações humanas. Petrópolis: Vozes, 2005.

Saberes docentes e formação profissional. Petrópolis: Vozes, 2002.

Enviado em: 15. 01.13

Aceito em: 27. 06. 13 